\title{
ANALISA RANCANG BANGUN TURBIN TENAGA MAGNET SEDERHANA SEBAGAI SUMBER LISTRIK SKALA RUMAH TANGGA
}

\author{
SUMARNO \\ Program Studi Teknik Mesin, Fakultas Teknik \\ Universitas Muhammadiyah Tangerang \\ Jl. Perintis Kemerdekaan I/33, Cikokol, Kota Tangerang \\ Email: bagosumarno76@gmail.com
}

\begin{abstract}
ABSTRAK
Kebutuhan energi listrik terus bertambah seiring dengan pemenuhan kebutuhan hidup. Penyediaan sumber energi listrik yang ada di Indonesia pada saat ini sudah mulai mengalami keterbatasan. Pada saat-saat tertentu pembangkit listrik yang ada tidak lagi mampu supplai energi listrik. Pemadaman listrik bergantian pun dilakukan untuk kebutuhan pemenuhan energi listrik dari sumber pembangkit serta dampaknya sangat terasa bagi masyarakat, kebutuhan sumber pembangkit listrik bertenaga nuklir masih mengalami pro dan kontra. Dari permasalahan tersebut dapat dirumuskan pada bagaimana membuat model pembangkit listrik alternatif yang dapat diciptakan dengan pemanfaatan gaya tolak menolak magnet. Magnet dengan kutub sama yang ditempatkan pada baling-baling dinamo motor DC akan terjadi putaran keseimbangan gaya. Besar gaya gravitasi dan gaya tolak magnet adalah sama. Keseimbangan ini akan berubah apa bila ada energi penggerak yang mengganggu keseimbangan. Magnet akan bergerak disekitar keseimbangan saat terjadi gangguan. Bergeraknya magnet akan menimbulkan perubahan fluk magnet. Perubahan fluk disekitar kumparan akan menyebabkan arus induksi pada kumparan sehingga dapat digunakan sebagai sumber arus listrik. Gangguan keseimbangan dari dua magnet yang saling tolak-menolak dapat diperoleh medan magnet tersebut. Pada pembangkit listrik yang me manfaatkan gaya tolak menolak magnet dinamo motor DC sebagai penggerak magnet agar bisa berputar yang diakibatkan gaya tolakkan magnet.
\end{abstract}

Kata Kunci: Krisis energi, dinamo motor DC, Putaran rendah/tinggi, Magnet stator dan Magnet generator.

\section{PENDAHULUAN}

1. Latar Belakang

Perkembangan teknologi di era globalisasi saat ini berimbas pada peningkatan kebutuhan energi listrik yang sangat besar, baik itu di negara maju maupun negara berkembang seperti indonesia. Pembangkit listrik terbarukan atau energi alternatif merupakan pilihan terbaik untuk memenuhi kebutuhan energi listrik dunia mengingat mahal dan langkanya energi minyak bumi yang selama ini selalu menjadi pilihan utama pada sistem pembangkitan energi listrik.

Sekarang ini kebutuhan energi listrik sangat diperlukan, karena banyak barang-barang yang dibutuhkan manusia yang sumber energi- nya adalah energi listrik. Oleh karena itu, manusia berusaha menemukan berbagai cara untuk menghasilkan energi listrik. Sampai sekarang ini manusia telah menemukan berbagai cara untuk menghasilkan energi listrik, antara lain pembangkit listrik tenaga panas bumi, pembangkit listrik tenaga matahari, pembangkit listrik tenaga angin, dan masih banyak lagi. (Paksi, 2012)

Inovasi adalah suatu hal yang paling diperlukan bagi mahasiswa untuk merubah suatu masa ke masa yang lebih baik, penemuan yang berbeda atau belum ada sebelumnya. Ketika dunia mengalami permasalahan krisis energi listrik khususnya di pedesaan, suatu inovasi diikuti dengan penerapan sains dan teknologi 
dengan peluang besar dapat mengatasinya. Dari permasalahan krisis energi tersebut, kami tertarik untuk memecahkannya dengan menemukan cara lain untuk mendapatkan energi.

Oleh sebab itu berbeda dari yang sebelumnya seperti pembangkit listrik tenaga air, udara, uap dan surya, kami ingin menerapkan hal tersebut dengan membuat suatu alat yang dapat menghasilkan energi listrik dengan sistem turbin melalui tenaga magnet dan akan kami kaji pada halaman berikutnya. Untuk membangkitkan listrik dari energi alternatif yang ada biasanya tetap menggunakan generator untuk proses pembangkitan listrik.

Penyusunan tugas akhir ini bertujuan untuk memaparkan tentang penggunaan magnet dalam pemanfaatanya untuk membangkitkan energi listrik. Pemanfaatan magnet sangat berguna dalam penerapan pembangitan listrik skala kecil, karena generator magnet mempunyai keunggulan yang tak terduga ketika hanya mendapatkan putaran rendah atau tinggi tapi bisa mengeluarkan energi listrik yang cukup besar. Perancangan alat pembangkit listrik menggunakan magnet skala rumah sederhana ini dapat bermanfaat bagi penerapan pencahayaan bagi daerah-daerah terpencil yang sangat susah untuk dijangkau dalam proses penyaluran listrik negara. Kali ini saya akan menjelaskan salah satu diantara banyak pembangkit listrik, yaitu pembangkit listrik tenaga tolakan magnet. Pembangkit listrik tenaga tolakan magnet adalah pembangkit listrik yang memanfaatkan kekuatan tolakan magnet untuk menghasilkan energi listrik. Kelebihan pembangkit listrik ini dibandingkan pembangkit listrik lainnya adalah bebas bahan bakar minyak, tidak tergantung pada air/angin/matahari, bebas suara berisik, dan ramah lingkungan. (Paksi, 2012)

\section{Identifikasi Masalah}

Dari pembahasan diatas di identifikasi dalam proses rancang bangun turbin tenaga magnet sederhana yaitu sebagai berikut ini:

1) Bagaimanakah cara menemukan jenis magnet yang sesuai.

2) Bagaimanakah prinsip kerja turbin magnet sederhana.

\section{Rumusan Masalah}

Dari pokok-pokok pembahasan masalah untuk membuat energi alternatif diatas maka akan dapat dirumuskan sebagai berikut:
1) Bagaimanakah medan magnet dapat menggerakkan turbin tenaga magnet sederhana?

2) Apakah magnet dapat mempertahankan kemagnetannya dalam jangka waktu yang cukup panjang?

3) Apakah magnet dapat menjadi salah satu solusi dalam permasalahan krisis energi listrik?

\section{Tujuan Penelitian}

Tujuan penelitian dalam penulisan penelitian ini diantaranya adalah:

1) Menerapkan ilmu pengetahuan tentang konversi energi yang diperoleh dari bangku perkuliahan dan mengembangkannya.

2) Merencanakan dan membuat turbin magnet sederhana, sehingga dapat dipergunakan untuk praktikum dilaboratorium tenik mesin.

3) Untuk melatih dan menuangkan kreatifitas dalam berpikir serta memberikan inovasi positif kepada para pembaca tentang ilmu pengetahuan konversi energi.

4) Dari hasil penelitian ini adalah untuk menemukan suatu inovasi baru dengan menggunakan medan magnet sebagai sarana utama untuk menghasilkan energi listrik.

Manfaat penelitian yang diperoleh dari penyusunan laporan penelitian ini adalah sebagai berikut:

1) Memberikan informasi tentang bagaimana cara kerja sistem turbin magnet sederhana sebagai sarana energi alternatif yang dapat dipergunakan.

2) Bagi pembaca, dapat dijadikan sebagai masukan positif bagi yang ingin mempelajari dan mengembangkan sistem turbin magnet sederhana.

3) Bagi akademik, rancang turbin magnet sederhana bisa menjadi media pelatihan bagi mahasiswa untuk penggunaan praktikum dalam media perkuliahan dilaboratorium teknik mesin

\section{LANDASAN TEORI}

\section{Landasan Teori Magnet}

Magnet atau magnit adalah suatu obyek yang mempunyai suatu medan magnet. Asal kata magnet diduga dari kata magnesia yaitu 
nama suatu daerah di Asia kecil. Menurut cerita di daerah itu sekitar 4.000 tahun yang lalu telah ditemukan sejenis batu yang memiliki sifat dapat menarik besi atau baja atau campuran logam lainnya.Benda yang dapat menarik besi atau baja inilah yang disebut magnet.

Magnet dapat menarik benda lain, beberapa benda bahkan tertarik lebih kuat dari yang lain, yaitu bahan logam. Namun tidak semua logam mempunyai daya tarik yang sama terhadap magnet. Medan magnet terdapat ruangan disekitar kutub magnet,yang gayanya bisa tarik-menarik dan tolak-menolaknya masih dirasakan oleh magnet lain. (Budiman \& Arias, 2011)

Di dalam kehidupan sehari-hari kata "magnet" sudah sering kita dengar, namun sering juga berpikir bahwa jika mendengar kata magnet selalu berkonotasi menarik benda.Untuk bisa mengambil suatu barang dari logam (contoh obeng besi) hanya dengan sebuah magnet, misalkan pada peralatan perbengkelan biasanya dilengkapi dengan sifat magnet, sehingga memudahkan untuk mengambil benda yang jatuh di tempat yang sulit dijangkau oleh tangan secara langsung.

Bahkan banyak peralatan yang sering digunakan, antara lain bel listrik, telepon, dinamo, alat-alat ukur listrik, kompas yang semuanya menggunakan bahan magnet. Magnet dapat dibuat dari bahan besi, baja, dan campuran logam serta telah banyak dimanfaatkan untuk industri otomotif dan lainnya. Sebuah magnet terdiri atas magnet-magnet kecil yang memiliki arah yang sama (tersusun teratur), magnet-magnet kecil ini disebut magnet elementer.

Pada logam yang bukan magnet, magnet elementernya mempunyai arah sembarangan (tidak teratur) sehingga efeknya saling meniadakan yang mengakibatkan tidak adanya kutub-kutub magnet pada ujung logam. Setiap magnet memiliki dua kutub, yaitu: utara $(\mathrm{N})$ dan selatan (S). Kutub magnet adalah daerah yang berada pada ujung-ujung magnet dengan kekuatan magnet yang paling besar berada pada kutub-kutubnya.

Besi dan baja adalah dua contoh dari materi yang mempunyai daya tarik yang tinggi oleh magnet.Sedangkan oksigen cair adalah contoh materi yang mempunyai daya tarik yang rendah oleh magnet. Satuan intensitas magnet menurut sistem metrik Satuan Internasional (SI) adalah Tesla dan SI unit untuk total fluks magnetik adalah weber $\left(1 \mathrm{weber} / \mathrm{m}^{2}\right.$ $=1$ tesla) yang mempengaruhi luasan satu meter persegi. (Halliday\&Resnick, 2005)

\section{Bagian-Bagian Magnet}

Pada magnet terdapat beberapa bagianbagian, diantaranya adalah sebagai berikut ini:

1) Kutub Magnet

Bagian magnet yang mempunyai gaya tarik terbesar disebut kutub magnet Magnet selalu mempunyai dua kutub. Hal ini dapat diketahui bila sebuah magnet batang dicelupkan ke dalam serbuk besi. Dibagian tengah (daerah netral) tidak ada serbuk besi yang melekat, sedangkan bagian ujung makin banyak serbuk besi yang melekat pada magnet.Bagian yang banyak dilekati serbuk besi merupakan kutub magnet.Hal ini menandakan, gaya magnet yang paling besar berada di ujun-ujung magnet.

Kutub utara dan kutub selatan magnet setiap magnet, apapun bentuknya selalu mempunyai kutub utara dan selatan. Dengan mengamati magnet jarum yang berputar pada porosnya, misalnya kompas. Dalam keadaan diam, salah satu ujung magnet akan menunjukan ke arah utara, sedangkan ujung yang lainya menunjuk ke arah selatan. Ujung kompas yang menunjuk ke arah utara disebut kutub utara dan ujung magnet yang mengarah selatan disebut kutub selatan.(Budiman \& Arias, 2011)

\section{2) Sumbu Magnet}

Sumbu magnet yaitu garis yang menghubungkan antara kedua kutub magnet, seperti pada gambar dibawah ini dijelaskan arah sumbu magnet untuk bisa mengetahui bagaimana proses arah sumbu magnet dilihat secara visual atau gambar.

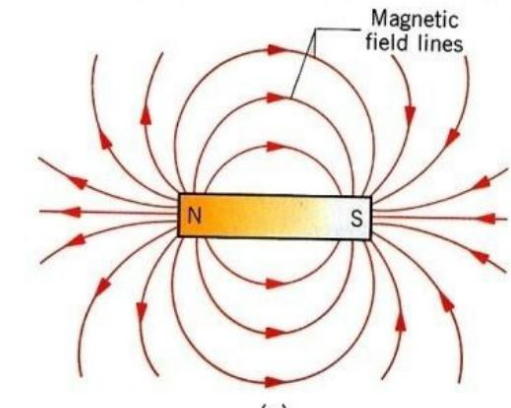

Copyright John Wiley d Son

(a)

Gambar 1. Sumbu Magnet

Sumber:Suyoso, 2003. 


\section{3) Magnet Elementer}

Setiap benda magnetik pada dasarnya terdiri dari magnet-magnet kecil yang disebut magnet elementer.Magnet elementer adalah magnet yang paling kecil yang berupa atom. Suatu benda akan bersifat magnet jika magnetmagnet elementernya mempunyai arah yang cenderung sama/ beraturan dan benda yang tidak mempunyai sifat magnet jika magnetmagnet elementernya mempunyai arah acak (sembarang).

Pada sebuah magnet, magnet-magnet elementernya tersusun rapi dan menunjuk arah yang sama, sehingga menimbulkan kutubkutub magnet. Antar magnet elementer tersebut terdapat gaya tolak-menolak dan gaya tarik-menarik. Akan tetapi, di bagian ujung magnet hanya terdapat gaya tolak-menolak. Itulah sebabnya pada ujung-ujung magnet terdapat gaya magnet paling kuat sedangkan bagian tengahnya lemah. (Budiman \& Arias, 2011)

Pada benda bukan magnet, magnet-magnet elementernya tersusun dengan arah yang berlainan atau arah yang acak sehingga tidak menimbulkan kutub magnet, karena arahnya tidak beraturan, gaya tarik-menarik dan tolakmenolak antar magnet elementer saling meniadakan. Itulah sebabnya pada besi bukan magnet tidak terdapat gaya magnet (sifat magnet). Dibawah ini adalah gambar garisgaris magnet sesuai dengan arah yang terjadi pada magnet tersebut.

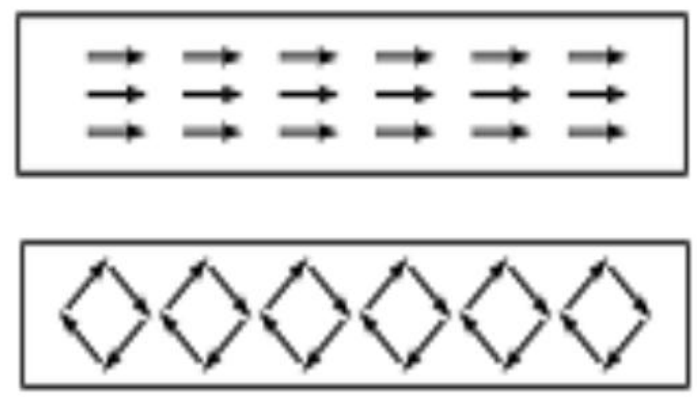

Gambar 2. Susunan magnet elementer besi/baja sebelum dan sesudah menjadi magnet.

Sumber:Suyoso, 2003.

\section{Medan Magnet}

Medan magnet terdiri dari garis-garis fluks imajiner yang berasal dari partikel bermuatan listrik yang bergerak atau berputar. Contohnya partikel proton yang berputar dan pergerakan elektron yang mengalir pada kawat dalam bentuk sirkuit elektronik. Seperti gambar dibawah ini adalah:

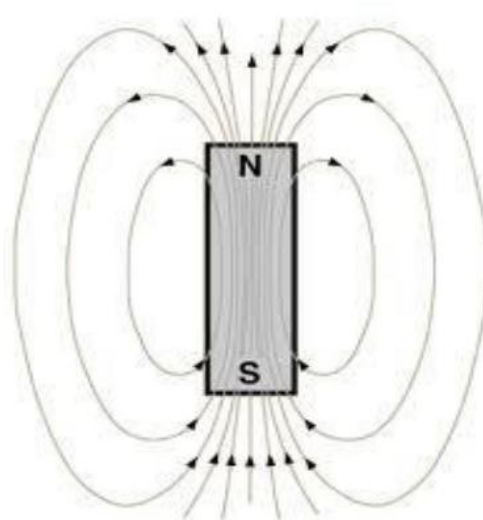

Gambar 3. Fluks Medan Magnet

Sumber:Suyoso, 2003.

Secara garis besar ada dua jenis magnet berdasarkan bagaimana medan magnetnya tercipta, yaitu:

1) Magnet permanen

Magnet permanen tidak tergantung akan adanya pengaruh dari luar dalam menghasilkan medan magnetnya. Magnet ini dapat dihasilkan oleh alam atau dapat dibuat dari bahan feromagnetik (bahan yang memiliki respon yang kuat terhadap medan magnet).

\section{2) Elektromagnet}

Elektromagnet adalah magnet yang medan magnetnya tercipta karena adanya arus listrik yang mengalir.Semakin besar arus yang diberikan, maka semakin besar pula medan magnet yang dihasilkan. (Budiman \& Arias, 2011)

\section{Bentuk-bentuk Medan Magnet}

\section{1) Medan Magnet Pada Kawat Lurus}

Bentuk garis medan magnet pada kawat panjang yang dialiri arus listrik berbentuk lingkaran konsentris mengelilingi kawat tersebut. Arah dari medan magnetnya tegak lurus terhadap kawat dan searah dengan jari-jari pada tangan kanan yang ditekuk, dan arah arusnya sesuai dengan arah ibu jari. Seperti pada gambar dibawah ini:

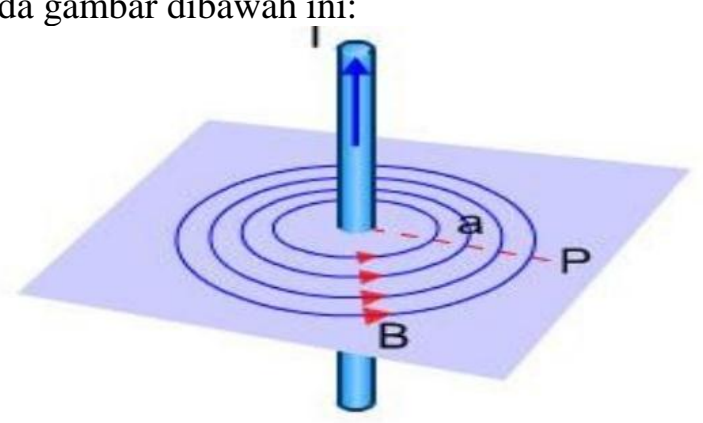

Gambar 4. Garis Medan Magnet Pada Kawat Lurus. Sumber:Suyoso, 2003. 


\section{2) Medan Magnet Pada Kawat Berbentuk Loop}

Arus listrik yang mengalir pada kawat berbentuk loop menghasilkan medan magnet lebih terpusat pada bagian tengah dibandingkan pada bagian luar loop. Seperti pada gambar dibawah ini yang sudah dijelaskan:

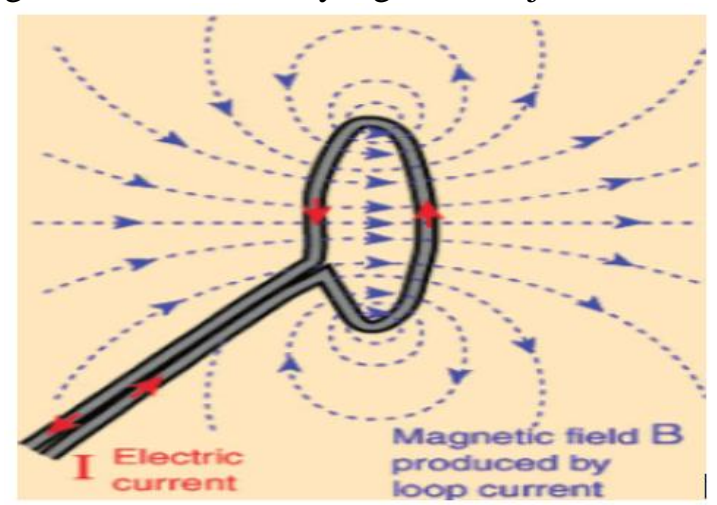

Gambar 5. Medan magnet pada kawat loop. Sumber:Suyoso, 2003.

\section{3) Medan Magnet Pada Magnet Batang}

Medan magnet pada sebuah batang magnet berbentuk garis tertutup.Melalui hasil konvensi, arah medan magnet keluar dari kutub utara $(\mathrm{N})$ menuju kutub selatan (S). Seperti pada gambar dibawah ini:

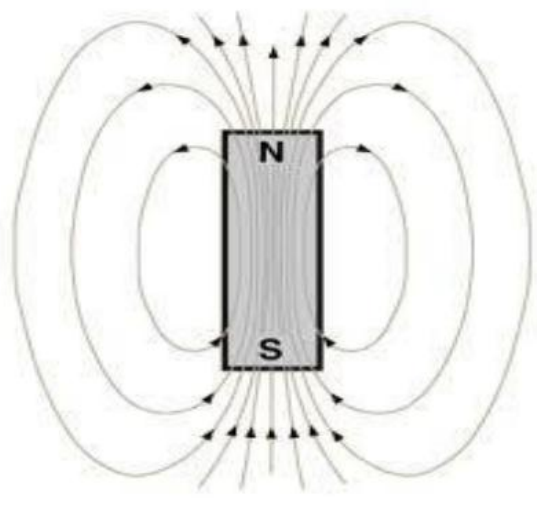

Gambar 6. Medan magnet pada magnet batang. Sumber:Suyoso, 2003.

\section{4) Medan Magnet Pada Solenoid}

Solenoid adalah kawat berarus listrik berbentuk loop yang biasanya dililitkan pada inti dari besi sehingga menghasilkan medan magnet. Medan magnet yang seragam dihasilkan pada pusat solenoid, sedangkan medan magnet yang terbentuk diluar solenoid lebih lemah dan divergen. Seperti pada gambar dibawah ini:

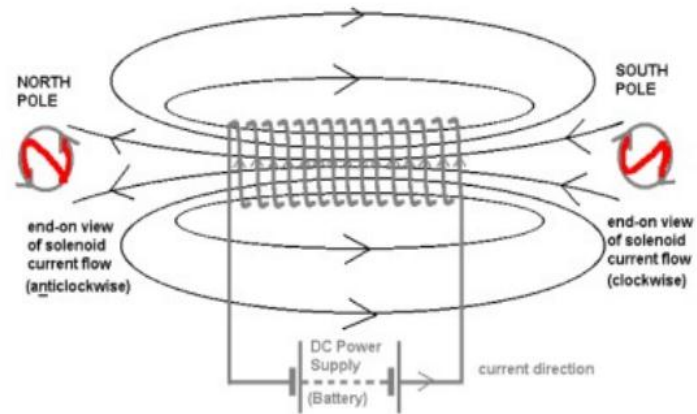

Gambar 7. Medan magnet pada solenoid. Sumber:Suyoso, 2003.

\section{4) Medan Magnet Pada Bumi}

Meskipun pola medan magnet bumi mirip dengan medan magnet batang yang jauh terkubur di dalam bumi. Bumi memiliki banyak kandungan bijih besi jauh di bawah permukaan bumi, tetapi karena suhu yang sangat tinggi di dalam inti bumi mencegah magnetisasi permanen. Para ilmuan mempertimbangkan bahwa sumber medan magnet bumi berasal dari arus konveksi dalam inti bumi, hal itu disebabkan oleh peredaran ion atau electron pada besi cair di inti bumi. Arah medan magnetnya serupa dengan arah medan magnet pada kawat berbentuk loop. Seperti pada gambar dibawah ini yang akan di uraikan \& dijelaskan:

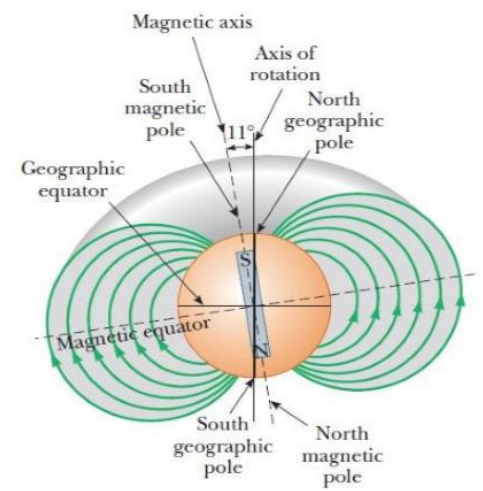

Gambar 8. Medan magnet pada bumi Sumber:Suyoso, 2003.

\section{METODELOGI PENELITIAN}

Dalam penelitian ini, pengumpulan data dilakukan dengan cara studi literature (perpustakaan), melakukan ekperimen, survey ke lapangan dan melakukan pengamatan tentang turbin magnet sederhana. Kemudian dilakukan percobaan bentuk visual rancang bangun turbin magnet sederhana ini, setelah itu dilakukan pengujian dalam perencanaan agar sesuai dengan yang direncanakan. 


\section{Konsep Perencanaan}

Konsep perencanaan turbin magnet sederhana ini mempunyai langkah-langkah yang dapat digambarkan oleh diagram alir, hal itu karena merupakan suatu gambaran utama yang dipergunakan untuk dasar dalam bertindak. Pada perancangan diperlukan suatu diagram alir yang bertujuan untuk mempermudah dalam pelaksanaan rancang bangun turbin magnet sederhana.

Proses perencanaan penelitian dengan judul rancang bangun turbin magnet sederhana memuat tentang bagaimana prinsip kerja dari turbin magnet sederhana yang pengoprasiannya mengunakan tenaga tolakan magnet untuk bisa menggerakkan dinamo sebagai generatornya yang menghasilkan arus listrik dari putaran generator yang digerakkan oleh tenaga tolakkan magnet.

Komponen-komponen Utama:

a) Magnet Permanen.

Magnet permanen adalah suatu bahan yang dapat menghasilkan medan magnet yang besarnya tetap tanpa adanya pengaruh dari luar atau disebut magnet alam karena memiliki sifat kemagnetan yang tetap. Magnet yang digunakan dalam jenis magnet neodymium, merupakan magnet tetap yang paling kuat. Salah satu karakteristik utama dari magnet permanen adalah memiliki kurva histerisis yang lebar, oleh karena itu magnet permanen disebut juga dengan magnet bahan keras.

Hal ini akan berdamapak pada daya yang dihasilkan generator turbin magnet nantinya, semakin besar daya tolak atau tarik magnet maka akan semakin besar induksi magnet yang dihasilkan dan juga untuk tegangan yang dihasilkan. Seperti gambar dibawah ini:

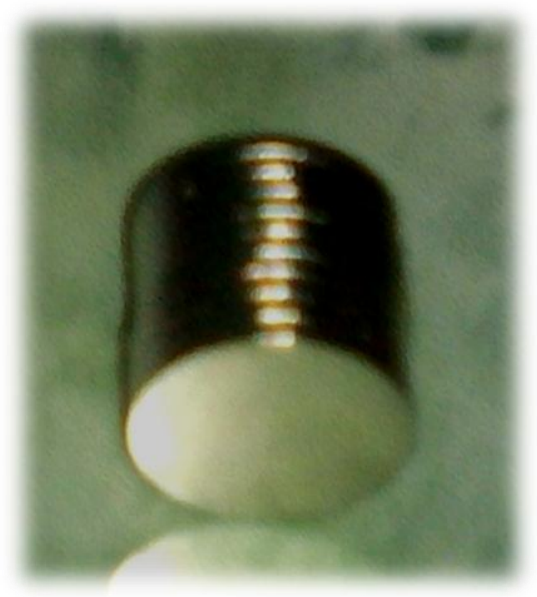

Gambar 9. Neodymium Magnet.

\section{b) Dinamo $12 v(D C)$.}

Dinamo $12 \mathrm{v}$ (DC) atau motor DC adalah jenis motor listrik yang bekerja menggunakan sumber tegangan DC atau motor arus searah sebagaimana namanya dalam hal ini menggunakan arus langsung dan tidak langsung. Motor DC digunakan pada penggunaan khusus dimana diperlukan penyalaan torque yang tinggi atau percepatan yang tetap untuk kisaran kecepatan yang luas, maka hal itu pula yang saya gunakan untuk dijadikan generator agar hasil pergerakan dari tolakan tenaga magnet bisa berputar dengan kecepatan maxsimal sehingga menghasil arus listrik. Dinamo 12v (DC) atau motor DC yang dijadikan sebagai generator turbin tenaga magnet seperti gambar dibawah ini:

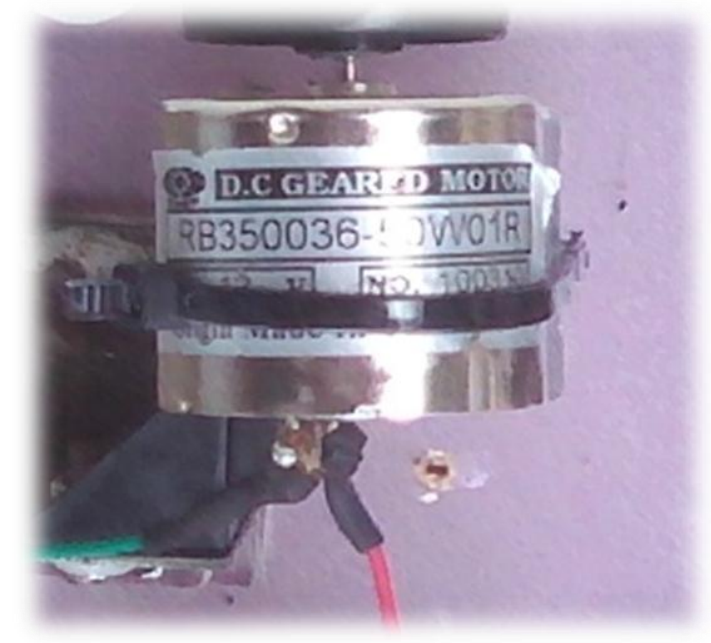

Gambar 10. Dinamo 12v (DC).

\section{d) Transformator}

Transformator atau yang disebut trafo adalah sebuah alat yang mentransfer atau mensupply energi antara 2 sirkuit yang melalui induksi elektromagnetik. Transformator atau trafo memungkinkan untuk digunakan sebagai perubahan tegangan (manaikkan atau menurunkan) tegangan arus listrik bolak-balik dari 1 tingkat ke tingkat lainnya dari input ke input alat tertentu, untuk menyediakan kebutuhan yang berbeda dari suatu arus sebagai sumber arus cadangan, atau bisa juga digunakan untuk mencocokkan impedansi antara sirkuit elektrik yang tidak sinkron untuk memaksimalkan antara 2 sirkuit. Hal ini memungkinkan terjadinya pertambahan daya arus listrik yang terjadi dari sebuah benda yang memiliki arus lisrik yang tidak stabil. 


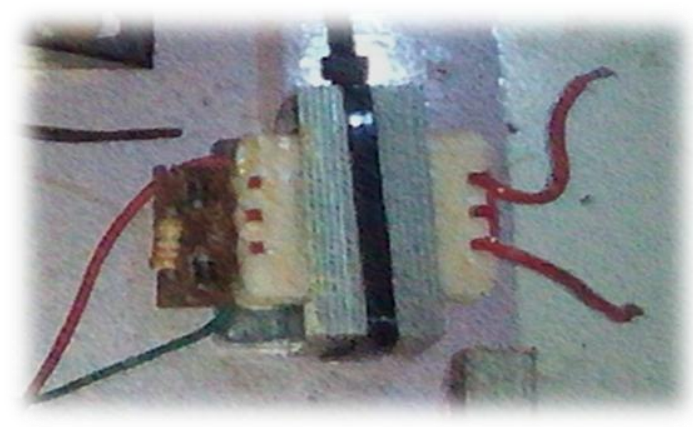

Gambar 11. Transformator atau trafo.

\section{e) Dioda 4 Kaki}

Dioda 4 kaki merupakan sebuah komponen yang berisi 4 buah diode yang berguna untuk mengatur arah polaritas DC yang keluar dari kaki DC agar tidak terjadi pembalikan fase saat sumber arus listrik AC dibalik atau diputar. Tidak ada perbedaan pada cara kerja dioda jika di bandingkan dengan doida biasa. Namun dioda ini memudahkan saat pemasangan karena rangkaian diode tersebut telah tertera sesuai dengan polaritasnya. Sehingga tidak perlu lagi mengatur arus sendiri. Seperti pada gambar dibawah ini:

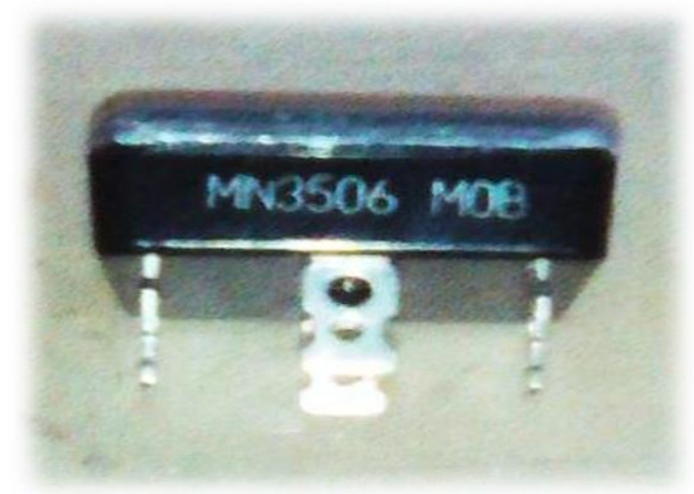

Gambar 12. Dioda 4 Kaki.

\section{f) Elco (Electrolit Condenser)}

Elco (Electrolit Condenser) adalah salah satu kapasitor jenis yang memiliki 2 kutub pada kaki-kakinya, kapasitor ini bisa juga disebut jenis kapasitor polar. Jadi untuk pemasangan elco ini tidsk boleh terbalik sebab kaki satu dengan yang lainnya berbeda. Sebuah elco memliki 2 kaki yakni positif (+) dan negatif (-), setiap elco memliki tegangan yang berbeda-beda biasanya pada bodinya tertulis batas tengan maxsimal. Jika batas tengangan elco melebihi kapasitas maka elco tersebut akan mengalami kerusakkan bahkan bisa sampai meledek.Pada umumnya sebuah elco memiliki funsi untuk menyimpan arus listrik DC. Namun pada prakteknya elco memiliki fungsi yang beragam mulai dari filter atau penyaring, sebagai kopling penghemat daya listrik, sampai dengan pembangkit frekuensi, tidak heranjika elco dapat ditemukan disetiap rangkaian elktorika. Dibawah ini adalah salah satu gambar elco yang digunakan.

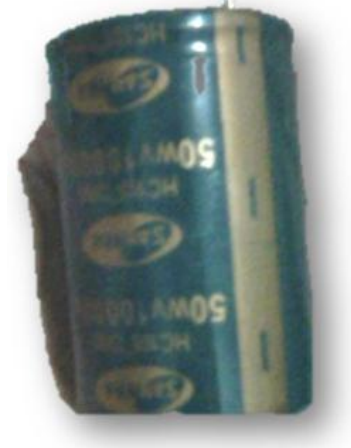

Gambar 13. Elco (Electrolit Condenser).

\section{g) Resistor}

Resistor adalah komponen elektronika yang memiliki 2 pin dan didesain untuk mengatur tegangan listrik serta berfungsi juga untuk menghambat atau membatasi aliran listrik yang mengalir dalam suatu rangkaian elektronika. Sebagai mana fungsinya resistor yang sesuai namanya bersifat resistif dan termasuk salah satu komponen elektronika dalam katagori komponen pasif.

\section{Prosedur Perancangan}

Dalam proses pembuatan rancang bangun turbin magnet sederhana harus melakukan tahapan-tahapan sebagai prosedur dalam proses pembuatan turbin magnet sederhana, diantaranya sebagai berikut ini:

a) Melakukan Persiapan

Pada tahap persiapan ini hal-hal yang dilakukan antara lain adalah studi pustaka tentang materi-materi yang berkaitan dengan turbin magnet sederhana dan rangkaian atau alur apa saja tahapan dalam pembuatan turbin magnet sederhana. Pada tahap persiapan ini juga dilakukan konsultasi dengan para ahli dan narasumber lain yang berkompeten serta menentukan alat dan bahan yang digunakan dalam proses perancangannya.

\section{b) Tahap Perancangan}

Pada tahap ini dilakukan pemilihan material magnet yang tepat, disini digunakan magnet jenis neodymium dengan kerapatan fluks paling besar yaitu 13500 Tesla, kemudian pemilihan rotor tatakan magnet diameter besar dengan kondisi dimana generator diameter terkecil akan menghasilkan 
putaran tinggi serta paling kuat. Dari pembahasan tersebut harus menghitung besar GGM gaya gerak magnet yang muncul pada generator nantinya dengan $\varepsilon=$ GGM induksi, $\varphi=$ fluks per kutub, $\mathrm{f}=$ putaran per sekon, $\mathrm{N}=$ jumlah lilitan kumparan, $\mathrm{N}_{\mathrm{k}}=$ Jumlah kumparan, $\mathrm{N}_{\mathrm{ph}}=$ jumlah fasa, $\mathrm{N}_{\mathrm{p}}=$ jumlah pasangan kutub, dan $\mathrm{C}=$ koefisien rangkaian. Setelah ditemukan besar GGM induksi, maka dapat di hitung besar daya out putan pada generator.

\section{Tahap Pembuatan Prototipe}

Pada tahap ini dilakukan pembuatan prototipe rangkaian penyearah untuk digunakan merubah tegangan AC ke pada tegangan DC dengan menggunakan jembatan dioda. Kemudian tahap pertama melakukan pembuatan generator stator, yang pertama dinamo 3 volt dengan magnet 12 biji, dan selanjutnya ditempatkan pada dudukan berbentuk lingkaran yang mengelilingi, begitu juga untuk membuat generator stator yang mengunakan dinamo 12 volt yang berisi magnet, setelah itu dilakukan penyatuan antara bagian generator rotor dan generator stator dengan menggunakan as sebagai poros untuk berputar.

Setelah ke 2 generator selesai dibuat, keluarannya disambungkan ke trafo step down 12 volt dan keluaran dari trafo akan disambungkan ke penyearah untuk menghasilkan tegangan DC. Seperti pada gambar dibawa ini:

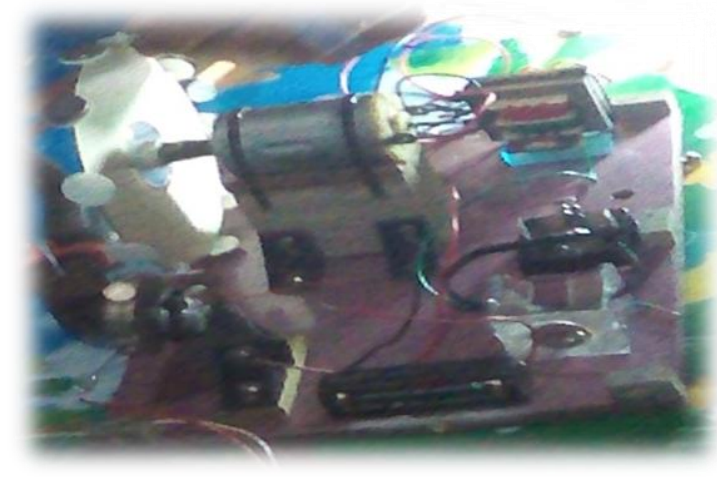

Gambar 14. Prototipe Turbin Magnet.

\section{Tahap Pengujian}

Pada tahap ini, generator dan rangkaian penyearah diuji dengan cara memasang turbin magnet atau turbin penggerak awal mula, agar unit generator dapat berputar dan menghasilkan daya listrik yang selanjutnya akan disearahkan oleh rangkain penyerah itu sendiri sehingga dihasilkan tegangan DC. Untuk mendapatkan tegangan arus listrik yang diharapkan harus diperhatikan putaran generator turbin magnet yang stabil dengan kecepatan tertentu dan juga dipengaruhi tenaga tolakan magnet itu sendiri. Pada tahap ini variabel yang diuji adalah tegangan generator, arus listrik yang keluar, kecepatan tenaga tolakkan magnet. Seperti pada gambar dibawah ini:

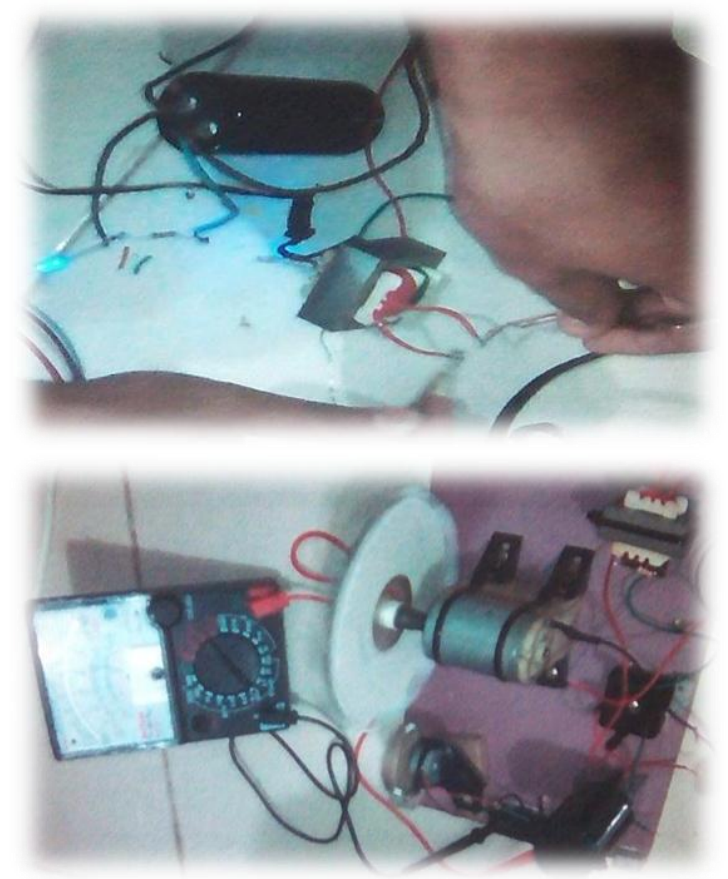

Gambar 15. Pengujian Rangkaian Arus Listrik dan Turbin Magnet.

\section{Analisa dan Pembahasan}

Pada tahap ini penulis mengumpulkan semua data-data sebanyak mungkin dari hasil analisa pungujian awal dan pengujian-pengujian yang terus-menerus dilakukan dan membandingkannya dengan hipotesa awal yang selalu gagal terus-menerus sampai bisa menemukan hasil yang cukup baik untuk menjawab masalah yang terjadi pada akhirnya akan diambil sebuah kesimpulan.

\section{HASIL DAN PEMBAHASAN \\ 1. Spesifikasi Rancang Bangun Turbin Magnet Sederhana}

Rancang bangun turbin magnet sederhana terdapat beberapa spesifikasi dan parameter yang dijadikan sebagai data masukkan untuk menyelesaikan Tugas akhir dalam pembuatan alat, dalam hal itu terdapat beberapa komponen dan spesikasi yaitu sebagai berikut ini:
1. Generator Turbin Magnet $=12$ Volt
2. Dinamo Penggerak Turbin Magnet $=12$ Volt
3. Frekuensi $=50 \mathrm{~Hz}$
4. Trafo $=1$ Phasa 
5. Batrai 2 buah

6. Putaran yang diinginkan

$=1,5$ Volt

$=500 \mathrm{rpm}$

$=10 \mathrm{Watt}$

\section{Pembahasan Konstruksi Turbin Magnet Sederhana}

Pada pembahasan turbin magnet sederhana mengenai bagaimana merancang kontruksi turbin magnet tersebut agar bisa menghasilkan karya yang baik, dalam hal itu terdapat berapa yang rangkaian diantaranya:

a) Generator Turbin Magnet

Generator turbin magnet permanen merupakan bagian yang bergerak yang terdiri dari kincir/piringan sebagai dudukan magnet permanen. Konstruksi generator magnet terdiri dari kincir/piringan magnet permanen. Magnet permanent hasil perancangan rakitan ini berjumlah 12 buah magnet permanen yang disusun melingkar dengan kutub yang dipasang belawanan.atau dengan kata lain mempunyai konfigurasi N-S-N-S, konfigurasi ini bertujuan agar terjadi gaya tarik menarik dan tolak menolak pada kumparan sehingga akan timbul induksi tenaga tolakkan elektromagnetik . Untuk pemasangan magnetnya sendiri hanya ditempel mengunakan lem pada kincir/piringan (tidak ditanam).

Magnet tersebut diletakan pada kincir/piringan dari $\mathrm{CD}$ dengan diameter $12 \mathrm{~cm}$. Bahan CD digunakan karena mempunyai konduktifitas yang ringan dan cukup kuat sehingga gaya tarik menarik atau tolak-menolak magnet dengan kincir/piringan cukup kuat agar poros generator turbin dapat berputar dengan cepat, jika dihubungkan dengan dinamo penggerak turbin magnet, sehingga putaran yang dihasilkan sempurna, agar kontruksi tidak goyang maka dipasang penguat. Seperti pada gambar di bawah ini merupakan gambar turbin magnet yang telah dirancang.

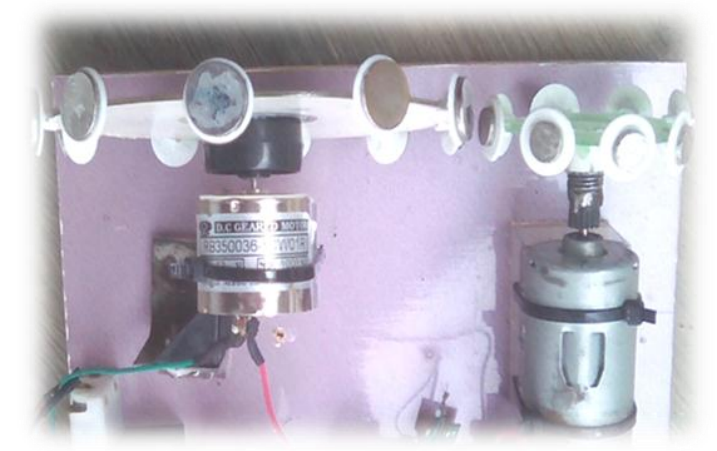

Gambar 16. Generator Turbin Magnet.

\section{b) Jumlah Magnet dan Putaran Generator Turbin Magnet}

Pada bagian ini akan dijelaskan hasil perancangan turbin magnet yang digunakan. Mengacu pada persamaan $=\frac{120 f}{p}$, bahwa jumlah berbanding terbalik dengan jumlah kutub, sehingga semakin banyak jumlah kutub yang digunakan, maka semakin kecil jumlah putaran per menit (rpm) yang dibutuhkan untuk menghasilkan arus listrik. Nilai $50 \mathrm{~Hz}$ digunakan karena merupakan standar frekuensi listrik yang digunakan di Indonesia. Sehingga jumlah putaran yang dibutuhkan untuk generator turbin magnet yang dirancang dengan jumlah kutub 12 buah adalah sebagai berikut:

$n=\frac{120 f}{p} \quad n=\frac{120 \times 50}{12}=\frac{6000}{12}=500 \mathrm{rpm}$

Jadi jumlah putaran yang dibutuhkan untuk menghasilkan frekuensi $50 \mathrm{~Hz}$ adalah 500 rpm.

\section{c) Jenis Magnet}

Jenis magnet yang digunakan dalam perancangan turbin magnet ini adalah jenis magnet permanen (Neodymium) dengan diameter $15 \mathrm{~mm} \times 3 \mathrm{~mm}$. Namun pada perencanaan ini, nilai $\mathrm{Br}$ yang diambil adalah nilai minimum agar mendapatkan hasil yang lebih maksimal. Seperti pada gambar dibawah ini:

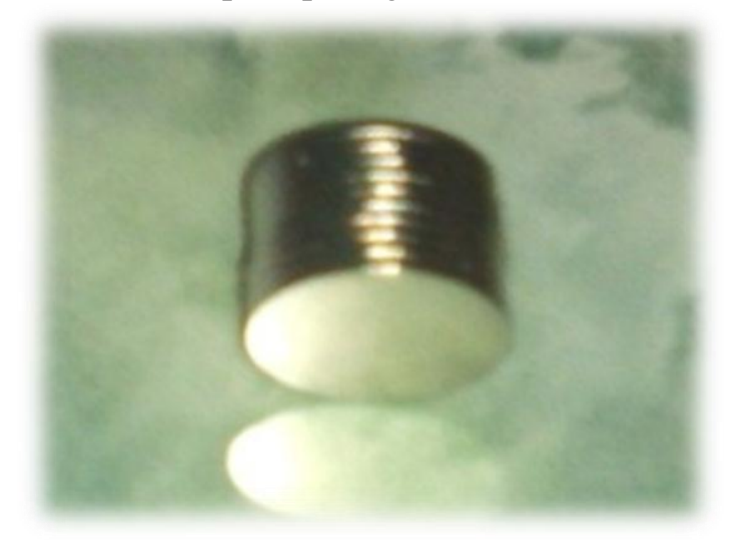

Gambar 17. Magnet Permanen (Neodymium).

Terdapat tiga material magnet permanen yang umum digunakan saat ini, yaitu:

1. Alniko, merupakan material campuran dari alumunium, nikel, kobalt dan besi

2. Keramik, merupakan material campuran dari ferit dan bahan lainnya, contohnya baarium ferit $\left(\mathrm{BaO} \quad x \quad 6 \mathrm{Fe}_{2} \mathrm{O}_{3}\right)$ dan stronium ferit $\left(\mathrm{SrO} \times 6 \mathrm{Fe}_{2} \mathrm{O}_{3}\right)$ 
3. Magnet dari material bumi langka seperti samarium kobalt ( $\mathrm{SmCo})$ dan besi-boronneodimimium $(\mathrm{NdFeB})$

Tabel 4.1 Spesifikasi beberapa bahan magnet permanen.

\begin{tabular}{|c|c|c|c|c|}
\hline Material Magnet & $\begin{array}{c}\text { Energi } \\
\text { Maksimum } \\
\text { Bhmax } \\
\text { (Joule) }\end{array}$ & $\begin{array}{c}\text { Kepadatan } \\
\text { Fluks } \\
\text { Magnet } \\
\text { (T) }\end{array}$ & $\begin{array}{c}\text { Daya } \\
\text { Tarik Hc } \\
(\mathrm{A} / \mathbf{m})\end{array}$ & $\begin{array}{c}\text { Temperatur } \\
\text { Kerja }\left({ }^{\circ} \mathrm{C}\right)\end{array}$ \\
\hline Keramik 5 & 3.4 & 3950 & 2400 & 400 \\
\hline Alniko 5 & 3.9 & 10900 & 620 & 540 \\
\hline Alniko cetak 8 & 5.3 & 8200 & 1650 & 540 \\
\hline Samarium Kobalt 20 & 20 & 9000 & 8000 & 260 \\
\hline Samarium Kobalt 28 & 28 & 10500 & 9500 & 350 \\
\hline Neodimium N45 & 45 & 13500 & 10800 & 80 \\
\hline
\end{tabular}

Sedangkan kurva histerisis beberapa bahan magnet dapat dilihat pada gambar:

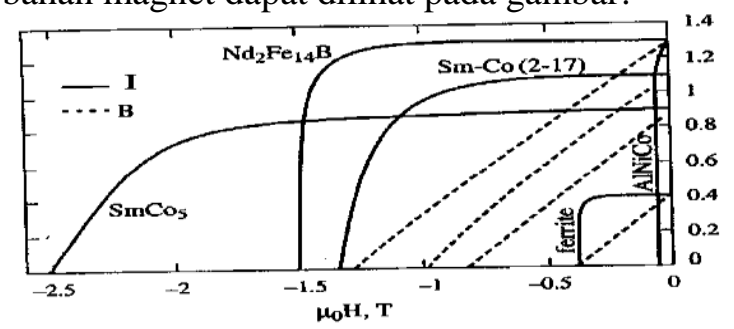

Gambar 18. Kurva karakteristik magnetik beberapa material magnet permanen.

Sumber: www.google.com

Grafik diatas merupakan penggambaran kurva histerisis dari berbagai macam jenis magnet untuk besar arus, fluks magnet, kerapatan fluks dan energi maksimal yang dapa dihasilkan oleh jenis magnet yang ada. Disini jenis neodymium merupakan jenis magnet yang paling besar kerapatan fluks dan energi yang dihasilkan dan yang paling rendah adalah magnet jenis ferrite.

\section{d) Konstruksi Dinamo Penggerak Turbin Magnet}

Konstruksi dinamo penggerak turbin magnet dipengaruhi oleh dimensi magnet yang digunakan sehingga harus diperhitungkan jarak antar magnet bagian dalam dan luar, keliling dinamo penggerak turbin magnet dan tebal kincir/piringan.

Hal pertama yang dilakukan adalah mengukur jarak antara magnet yaitu $15 \mathrm{~mm}$. Setelah itu menghitung keliling kincir/piringan dinamo penggerak turbin magnet bagian dalam menggunakan rumus:

$$
K=(l \times N m)+(J d x N m)
$$

Dengan,

$\mathrm{K}=$ Keliling

$\mathrm{L}=$ lebar magnet

$\mathrm{jd}=$ jarak antar magnet
Sehingga,

$$
K=(10 m m \times 12)+(15 m m \times 12)=300 \mathrm{~mm}
$$

Kemudian diperoleh nilai radius dalam dengan persamaan:

$$
R i=\frac{K}{2 \pi}=\frac{300 \mathrm{~mm}}{2 \times 31.4 \mathrm{~mm}}=47.77 \mathrm{~mm}
$$

Nilai radius dalam dapat digunakan untuk menghitung nilai radius luar kincir/piringan dinamo penggerak turbin dengan menggunakan persamaan:

$$
R o=R i+p=47.77 \mathrm{~mm}+29 \mathrm{~mm}=76.77 \mathrm{~mm}
$$

Untuk memberikan batas pada magnet agar tidak mudah berubah maka radius kincir/piringan ditambahkan $5 \mathrm{~mm}$ sehingga menjadi $81.77 \mathrm{~mm}$ dan keliling total piringan rotor menjadi:

$$
\begin{aligned}
K l=2 \pi \times R o & =2 \times 21.4 \mathrm{~mm} \times 81.77 \mathrm{~mm} \\
& =5135.156 \mathrm{~mm} \\
& =513.5156 \mathrm{~cm}
\end{aligned}
$$

Selanjutnya untuk menentukan posisi magnet pada piringan dinamo penggerak turbin, maka terlebih dahulu menghitung jarak antar magnet bagian luar yang mengacu pada persamaan:

$$
\begin{aligned}
\beta & =2 \alpha \\
\alpha & =\sin 15 \times R o=\sin 15 \times 76.77 \mathrm{~mm} \\
& =19.87 \mathrm{~mm} \\
\beta & =2 \times 19.87 \mathrm{~mm}=39.74 \mathrm{~mm}
\end{aligned}
$$

Maka jarak antara magnet bagian luar adalah:

$$
\begin{aligned}
j l=\beta-\left(2 \times \frac{1}{2} l\right) & =39.74 m m-\left(2 \times \frac{1}{2} 10\right) \\
& =29.74 m m
\end{aligned}
$$

Pada gambar di bawah ini merupakan penempatan magnet dapat dilihat dari sisi pemasangan magnet:

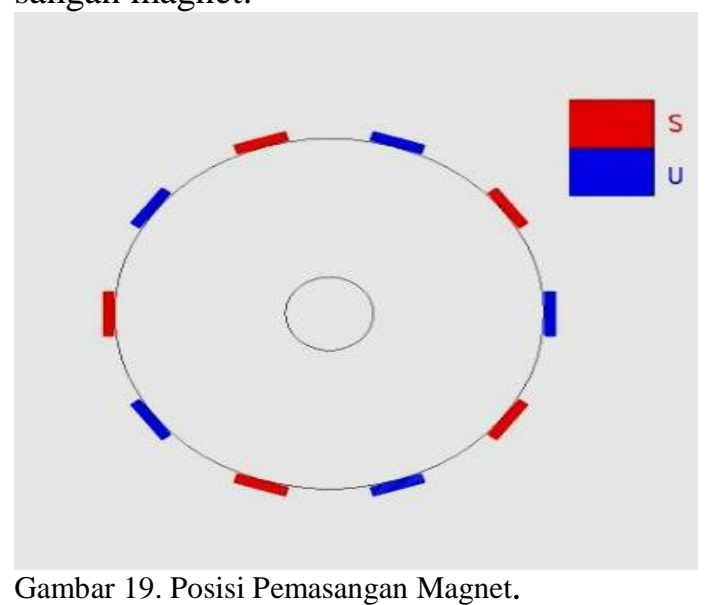




\section{Prinsip Kerja Turbin Magnet}

Kali ini saya akan menjelaskan salah satu prinsip kerja turbin magnet diantaranya, yaitu pembangkit listrik tenaga tolakan magnet. Pembangkit listrik tenaga tolakan magnet adalah pembangkit listrik yang memanfaatkan kekuatan tolakan magnet untuk menghasilkan energi listrik. Kelebihan pembangkit listrik ini dibandingkan pembangkit listrik lainnya adalah bebas bahan bakar minyak, tidak tergantung pada air/angin/matahari, bebas suara berisik, dan ramah lingkungan. Berikut adalah gambar pembangkit listrik tenaga tolakan magnet (turbin magnet).

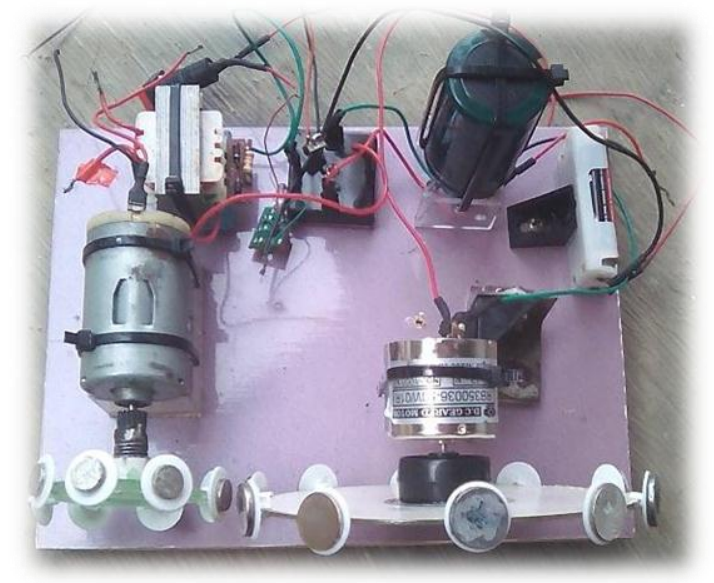

Gambar 20. Turbin Magnet.

Alat ini terbuat dari bahan yang mudah dicari. Bahan-bahan yang dibutuhkan untuk membuat alat ini adalah sebuah papan kayu atau triplek sebagai dasar atau alas, 4 buah baut untuk memasangkan alat dengan landasan, dimano 12 volt sebagai generator pembangkit arus listrik, 8 12 magnet kecil yang memiliki kekuatan tarik maupun tolak yang besar, sebuah magnet besar, sebuah lampu kecil, dan lem.

\section{KESIMPULAN}

1. Rancang bangun turbin tenaga magnet sederhana mampu menjadi solusi untuk menciptakan energi listrik alternatif. Hal itu disebabkan karena sifat magnet permanent ini memiliki sifat yang tetap, kuat dan jenis magnet yang digunakan adalah magnet neodinium.

2. Rancang bangun turbin magnet ini ramah lingkungan tidak menggunakan bahan bakar serta tidak menimbulkan suara bising.
3. Rancang bangun turbin magnet ini memanfaatkan kekuatan tolakan magnet untuk meggerakkan generator (dinamo) agar dapat menghasilkan tegangan arus listrik dengan daya yang sudah direncanakan yaitu sebesar 10 watt

\section{DAFTAR PUSTAKA}

Budiman, Aris. Desain Generator Magnet Permanen untuk Sepeda Listrik. Surakarta: Universitas Muhammadiyah Surakarta. 2011.

Dimas,W. J., Sukamdi, T., dan Karnoto. 2011. Jurnal. Perancangan Generator Fluks Aksial Putaran Rendah Magnet Permanen Jenis Neodymium (NdFeB) Dengan Variasi Celah Udara. Universitas Diponegoro. Semarang.

Halliday,D., \& Resnick, R. (2005). Fisika Jilid 3. Jakarta: Erlangga.

Nurhadi, Arif. 2011. Jurnal. Perancangan Generator Putaran Rendah Magnet Permanen Jenis FE Fluks Aksial. Universitas Diponegoro. Semarang.

Suyoso. (2003). Common Textbook Listik Magnet. Jakarta: JICA IMSTEP

Purnawan, B. S. 2012. Perancangan Pembangkit Listrik Sederhana Menggunakan Generator Mini Magnet Permanen. Universitas Pakuan. Bogor.

Pane, Ennopati. Studi Sistem Eksitasi Dengan Menggunakan Permanent Magnet Gernerator (Aplikasi Pada Generator Sinkron di PLTD PT. Manunggal Wiratama. Medan: Universitas Sumatra Utara. 2009.

Wildi, Theodore. Electrical Machines, Drives, and Power System Third Edition. New Jersey: Prentice-Hall International, Inc. 1997.

Zuhal. Dasar Teknik Tenaga Listrik dan Elektronika Daya. Jakarta: PT. Gramedia Pustaka Utama.1995. 